\title{
As diversas sonoridades do grupo de rock brasileiro 0 Terço: discussões sobre as identidades musicais nos anos 1970
}

The various sonorities of the Brazilian rock band "O Terço": discussions on the musical identities in the 1970's

Victor Henrique de Resende UFMG -vhrjedi@yahoo.com.br

Ana Cláudia de Assis UFMG - anaclaudia@ufmg.br 


\section{Resumo}

O artigo apresenta uma proposta analítica das sonoridades construídas pelo grupo brasileiro de rock O Terço, durante a década de 1970. Mostra-se que o grupo em questão não trouxe uma ideia fixa de música, ou melhor, de rock brasileiro. Com diversas influências do gênero rock, e de várias sonoridades já consideradas como parte da música brasileira, os músicos d'O Terço trouxeram suas representações de campo e cidade, tradição e modernidade, elogio ao rock e críticas ao contexto da ditadura civil-militar no Brasil. Tais ideias serão analisadas em algumas canções selecionadas para este estudo. Para tal, propõe-se conjugar as ferramentas metodológicas dos autores Bruce Baugh (1994), Marcos Napolitano (2002), Felipe Trotta (2008) e Paul Friedlander (2012), demonstrando como os elementos musicais estabelecem um jogo dinâmico com seu tempo histórico. Discutem-se, também, algumas teorias e problemáticas sobre identidade, por meio dos estudos de Fredrik Barth (1998), Stuart Hall (1998) e Miguel Alberto Bartolomé (2006). Com estes, procura-se apontar que a identidade é sempre construída dentro de um contexto, sendo, portanto, relacional.

Palavras-chave: sonoridade; identidade; rock brasileiro.

\section{Abstract}

This paper shows an analytical proposal of the sonorities built by the rock Brazilian band "O Terço", during the 70's. It is shown that the group, in question, did not bring the fixed idea of music, or rather, of Brazilian rock. With a diversity of influences from the rock style to several sonorities already considered part of the Brazilian music, "O Terço's" music brought their country and urban interpretation, tradition and modernity, praise to rock and criticism towards the Brazilian civil-military dictatorship scene. Such ideas will be analyzed through some songs selected for this study. To this end, it is proposed to conjugate the methodological tools from the authors Bruce Baugh (1994), Marcos Napolitano (2002), Felipe Trotta (2008) and Paul Friedlander (2012), showing how the musical elements establish a dynamic game with their historical time. It has also been discussed some theories and identity issues through Fredrik Barth (1998), Stuart Hall (1998) and Miguel Alberto Bartolomé (2006). With these, it is pointed that the identity is always built within the context, therefore, it is relational.

Keywords: sonority; identity; Brazilian rock.

Victor Henrique Rezende é músico, doutorando em Música pela Universidade Federal de Minas Gerais, sob orientação da Professora Dra. Ana Cláudia de Assis. Bolsista CAPES/Demanda Social. Graduado em História e mestre em História (História e Música) pela Universidade Federal de São João Del-Rei. Tem experiência na área de História da Música, História da Arte, História Cultural (música popular) e na área de ensino de música (violão e musicalização infantil).

Ana Cláudia Assis é professora da Escola de Música da UFMG onde desenvolve projetos de pesquisa/artísticos sobre a música dos séculos XX e XXI. Doutora em História e mestre em Práticas Interpretativas da Música Brasileira publicou, em 2015, o livro Os Doze Sons e a Cor Nacional: Conciliações estéticas e culturais na produção musical de César Guerra-Peixe. 


\section{Discussões metodológicas}

O presente artigo traz uma proposta analítica das sonoridades construídas pelo grupo brasileiro de rock O Terço, durante a década de 1970. Procura-se mostrar que o grupo não construiu apenas uma, mas várias identidades sonoras em sua produção musical.

As discussões dos autores Fredrik Barth (1998), Stuart Hall (1998) e Miguel Alberto Bartolomé (2006), apontam a identidade como um conceito sempre relacional, ou seja, a identidade é construída nas diversas relações sociais. Partindo dessas discussões, procura-se mostrar que a banda O Terço construiu, ao longo dos anos 1970, sua identidade sonora passando não por uma, mas por várias apropriações do gênero rock. Importante ressaltar que este gênero também apresenta várias vertentes ou subgêneros que, ao longo do texto, serão discutidos. Conforme será visto, o grupo O Terço possui alguns elementos sonoros que lhe conferem certa identidade musical. Nesse caso, tais elementos podem ser denominados de traços diacríticos, que, segundo Fredrik Brath, são os "sinais ou signos manifestos [...] que as pessoas procuram e exibem para demonstrar sua identidade, tais como o vestuário, a língua, a moradia, ou o estilo geral de vida" (BARTH, 1998, p.194). Barth, no caso, está preocupado com a formação e a permanência de grupos étnicos. Assim como Miguel Alberto Bartolomé, que trabalha com as etnogêneses1 dos diversos grupos humanos, tratando-se, pois, de construções culturais "das distintas experiências sociais e dos diversos sistemas simbólicos que os animam" (BARTOLOMÉ, 2006, p.40), Barth afirma que tanto a identidade quanto a cultura (termos inter-relacionados para os dois autores) podem apresentar traços de permanência dentro de um ou de vários contextos históricos. Os autores afirmam, também, que a identidade de um grupo e seus componentes culturais podem se modificar conforme as circunstâncias ou, como enfatiza Bartolomé, de acordo com "a configuração circunstancial de um dinamismo aberto à história" (BARTOLOMÉ, 2006, p.41).

Embora este artigo não trate de um estudo sobre etnicidade, mas de identidades sonoras, é possível identificar no grupo $\bigcirc$ Terço alguns traços que conferem certo reconhecimento musical por parte da mídia, público e da própria banda. Desse modo, o conceito de traço diacrítico de Barth pode ser articulado com o conceito de sonoridade do autor Felipe Trotta (2008), mais à frente discutido.

Desse modo, serão apresentadas as diversas possibilidades e combinações sonoras na produção artística do grupo. Para tanto, tomam-se, para a presente análise, algumas canções selecionadas de cinco produções fonográficas da banda, conforme mostrado adiante. Para a análise do material sonoro, propõe-se conjugar algumas ferramentas metodológicas dos autores Bruce Baugh (1994), Marcos Napolitano (2002), Paul Friedlander (2012) e Felipe Trotta (2008).

De acordo com a definição proposta por Felipe Trotta, entende-se sonoridade como "o resultado acústico dos timbres de uma performance, seja ela congelada em

10 conceito de etnogênese, segundo Bartolomé, visa dar conta do "processo histórico de configuração de coletividades étnicas como resultado de migrações, invasões, conquistas, fissões ou fusões" (BARTOLOMÉ, 2006, p. 39). Para o autor, a etnogênese (ou etnogêneses) não é um fenômeno recente, mas sempre existiu no decorrer da história humana. 
gravações (sonoras ou audiovisuais) ou executada 'ao vivo'" (TROTTA, 2008, p.3-4). Para o autor, sonoridade tem a ver com reconhecimento musical. Segundo Trotta:

Trata-se, portanto, de uma combinação de instrumentos (e vozes) que, por sua recorrência em uma determinada prática musical, se transforma em elemento identificador. Falamos em "baixo, guitarra e bateria" e imediatamente pensamos na estética musical do rock. Visualizamos um trio de instrumentistas - em silêncio - portando sanfona, triângulo e zabumba e esperamos a execução de um forró. Analogamente, ninguém espera que um quarteto de cordas (2 violinos, viola e violoncelo) vá tocar um reggae, um frevo ou um blues. Cada formação instrumental evoca um determinado ambiente musical, representado sonoramente em seu conjunto de instrumentos característicos que servem como elementos constitutivos de sua prática (TROTTA, 2008, p.4).

O autor, por sua vez, baseia-se na metodologia de Philip Tagg (1987) que, dentre vários apontamentos, busca os musemas numa produção musical. Segundo Tagg, esses musemas significam as unidades mínimas de identificação de uma canção (como melodia, harmonia, ritmo, entre outras) que permitem determinar um estilo ou gênero, podendo, inclusive, serem utilizados para comparação entre produções musicais. Acredita-se, contudo, que tal abordagem seja pertinente para determinar não uma, mas várias sonoridades da banda em estudo. Conforme será visto, não só a guitarra, o baixo e a bateria podem compor o que se chama de rock. Será mostrado que o grupo, aqui pesquisado, não combinou apenas esses instrumentos (guitarra, baixo e bateria) e que certas sonoridades que eles produziram não ficaram restritas às instrumentações consideradas típicas do rock. Portanto, identificar e analisar os musemas numa canção não é suficiente para se entender a produção musical do grupo considerado. Felipe Trotta se atém ao estudo do que ele denomina de gêneros musicais. Contudo, a banda $O$ Terço não se fixou em apenas uma forma de produzir e executar seu rock.

Dessa maneira, propõe-se conjugar outras metodologias. Testando a hipótese de que não é possível traçar um único método de análise para a música, sobretudo para a canção brasileira, adotam-se, também, os pressupostos metodológicos do historiador Marcos Napolitano, que estuda a música popular brasileira, do historiador do rock Paul Friedlander e do filósofo Bruce Baugh, que propõe pensar uma estética do rock.

Segundo Baugh (1994), podem-se averiguar algumas características materiais relevantes do gênero rock. Para o autor, três componentes importantes definem uma certa estética do rock: a performance dos tons como, por exemplo, os sons e ruídos executados na guitarra elétrica; a altura, onde é percebido que o rock se define por seu volume elevado; e, por fim, o ritmo: o rock é feito para dançar. Percebe-se, contudo, que a produção do grupo $O$ Terço extrapola esses elementos básicos propostos pelo autor. Suas discussões compreendem um excelente ponto de partida, porém, não são suficientes para uma abordagem do rock produzido pela banda em análise.

Do autor Marcos Napolitano (2002), utilizam-se suas diretrizes analíticas que visam articular letra e música. Seus pressupostos metodológicos subdividem-se em: a) organizar a ficha técnica das fontes (canções), destacando o gênero, o suporte, a origem, a data, a autoria, o conteúdo referente e o acervo, a fim de criar um banco de dados para 
as obras estudadas; b) articular códigos verbais e parâmetros musicais das composições selecionadas; c) analisar as canções como testemunhos da história sociocultural; d) decodificar os elementos constituintes das canções - letra, harmonia, melodia, ritmo e dinâmica - para uma análise minuciosa do enfoque histórico proposto; e) audição sistemática e repetida; f) analisar cada item das canções: letra, estrutura musical (melodia, harmonia e ritmo), sonoridades vocais, sonoridades instrumentais (timbres, dinâmicas e improvisações) e performances dos artistas; g) reorganizar todos os elementos das canções, elaborando uma síntese para verificar as hipóteses da pesquisa, ou seja, como as formas artísticas analisadas se relacionam com o desenvolvimento das formas sociais.

Por fim, adota-se a metodologia de Paul Friedlander denominada de "janela do rock" (FRIEDLANDER, 2012, p.14-15). O esquema desenvolvido pelo autor compreende analisar na canção: a) música - compreensão do conjunto, destacando quais instrumentos estão presentes, ênfase rítmica (o compasso dominante e quais instrumentos marcam esse compasso), estilo vocal, solo instrumental e estrutura harmônica (os acordes presentes na canção); b) letras - quais os principais temas da canção (como, por exemplo, amor romântico, sexo, alienação, justiça/injustiça, introspecção, música pop/ rock) e a história que é contada; c) histórico do artista - elementos da história pessoal e da carreira do artista que sejam relevantes para o entendimento da canção; d) contexto social - as influências do ambiente político, social e econômico para a criação artística, com destaque para a cultura jovem e sua relação com a sociedade, os movimentos políticos e culturais (luta por direitos civis, minorias, contraculturas alternativas etc.) e a questão da indústria musical, seu desenvolvimento e relações com os músicos; e) atitude - elementos de performance ao vivo dos artistas, seus atos e comportamentos em público.

Percebe-se, então, a possibilidade de articular as metodologias acima, sem perder o enfoque sobre as sonoridades. Conforme aponta Felipe Trotta, "a sonoridade, como qualquer parâmetro de análise musical, é um elemento indissociável de outros elementos musicais e não-musicais" (TROTTA, 2008, p.10). Contudo, procura-se demonstrar que os "elementos não-musicais", de que fala Trotta, também fazem parte do fazer musical de qualquer artista ou banda. Dessa forma, abordam-se, neste estudo, os parâmetros sonoros da canção, bem como todos os possíveis elementos que compõem a sua produção, compreendendo aquilo que Jean Molino chama de fato musical. Segundo o autor, "não há, pois, uma música, mas músicas. Não há a música, mas um facto musical. Este facto musical é um facto social total" (MOLINO, 1975, p.114).

Sendo assim, neste artigo consideram-se os diversos fazeres musicais como resultado de uma prática social e que envolve produção, consumo, sonoridades, organologia, iconologia, contexto social, político, cultural e econômico, performance e os discursos sobre a prática musical. Compreende-se, então, o conceito de fato musical como construção. Jean Molino aponta que o conceito e o conhecimento sobre música passa pelo estudo do som construído e reconhecido por uma cultura.

Aproximando as metodologias, acima citadas, e levando-se em consideração o conceito de música como construção cultural (MOLINO, 1975), é possível analisar a estrutura das canções, seu ritmo, melodia e harmonia (TROTTA, 2008; NAPOLITANO, 
2002; FRIEDLANDER, 2012), articular letra e música (NAPOLITANO, 2002; FRIEDLANDER, 2012), comparar e perceber recorrências sonoras (TROTTA, 2008), conjugar dados biográficos e discursos sobre o fazer musical do grupo (FRIEDLANDER, 2012), percebendo, assim, a(s) estética(s) desse rock (BAUGH, 1994). Abaixo, são apresentados alguns desses elementos. Como visto, essas metodologias apresentam pontos em comum. Desse modo, as canções ou músicas abordadas aqui são trabalhadas com base nessas diversas combinações metodológicas, procurando-se chegar às possíveis interpretações sobre a prática artística do conjunto O Terço.

\section{A banda $O$ Terço}

A banda $O$ Terço se formou em 1968, na cidade do Rio de Janeiro, com Sérgio Hinds no baixo, Jorge Amiden na guitarra e Vinícius Cantuária na bateria. Posteriormente, os artistas radicaram-se na grande São Paulo. Gravaram seu primeiro LP em 1970.2 A partir de 1971, Sérgio Hinds passa a atuar como violoncelista, levando suas referências da música erudita para o conjunto. Nesse mesmo ano, entra na banda Cesar de Mercês. Eles gravam um compacto com músicas como $O$ Visitante,3 defendida no VI Festival Internacional da Canção da TV Globo, que apresenta uma sonoridade orquestral, além da presença do violoncelo elétrico de Sérgio Hinds e da guitarra de três braços criada por Jorge Amiden (MELLO, 2003, p.391). Neste compacto há, também, o trecho, cantado pela banda, da Ária da Suíte em Ré maior de J. S. Bach, onde já é possível perceber um traço marcante do grupo: a combinação de vozes agudas com predomínio de falsetes. Esses recursos de voz aparecem ao longo de toda produção d'O Terço. Em 1973, lançam seu segundo disco,4 onde Sérgio Hinds assume novamente as guitarras, Cesar de Mercês, o baixo, e Vinicius Cantuária, a bateria. Em 1974, já sem Cantuária, o grupo conta com Luiz Moreno na bateria, Sérgio Magrão (que já trabalhava na banda como técnico de som) no contrabaixo e Flávio Venturini nos teclados. Inicialmente, eles apresentam essa formação para a gravação do primeiro LP da dupla Sá \& Guarabyra, de 1974, intitulado Nunca. 5 Mais tarde, com os discos Criaturas da Noite (1975)6 e Casa Encantada (1976),7 será esta a formação do grupo O Terço até o LP Mudança de Tempo,8 de 1978,

\footnotetext{
2 LP O Têrço, Forma, 1970, relançado pela gravadora Discobertas, CD, DB-059, 2010. Traz as seguintes faixas: Nã; Plaxe voador; Yes I do; Longe sem direção; Flauta; I need you; Antes de você...eu; Imagem; Meia noite; Saturday dream; Velhas histórias; Oh! Suzana.

3 Compacto O Têrço, Forma, C07.007, 1971, relançado pela gravadora Discobertas, CD, DB-060, 2010. Traz as seguintes faixas: O visitante; Adormeceu; Doze avisos; Mero ouvinte; Trecho da ária extraída da suíte em Ré maior (Bach).

4 LP Terço, Continental, SLP-10107, 1973. Traz as seguintes faixas: Deus; Você aí; Estrada vazia; Lagoa das lontras; Rock do Elvis; Amanhecer total.

5 LP Nunca, Odeon, SBRXLD-12.566, 1974. Traz as seguintes faixas: As canções que eu faço; $2 .^{a}$ canção da estrada; Justo momento; São Nicolau; Verão do cometa; Esses cabides vazios; Nuvens d'agua; Divina decadência; Voar é como o passarinho; Apreciando a cidade; Terras do sul; Coisa à toa.

6 LP Criaturas da Noite, Underground/Copacabana, COLP-12009, 1975. Traz as seguintes faixas: Hey amigo; Queimada; Pano de fundo; Ponto final; Volte na próxima semana; Criaturas da noite; Jogo das pedras; 1974.

7 LP Casa Encantada, Underground/Copacabana, COLP-12074, 1976. Traz as seguintes faixas: Flor de la noche; Luz de vela; Guitarras; Foi quando eu vi aquela lua passar; Sentinela do abismo; Flor de la noche II; Casa encantada; Cabala; Solaris; Voo da fênix; Pássaro.

8 LP Mudança de Tempo, Underground/Copacabana, COLP-12201, 1978. Traz as seguintes faixas: Não sei não; Gente do interior; Terças
} 
sem a participação de Flávio Venturini.

Na produção musical d'O Terço encontram-se canções que falam da natureza, do elogio ao rock e da condição dos sujeitos entre cidade e campo. Há, também, canções de crítica e de reflexão sobre a modernidade e referentes, mesmo que de forma sutil, ao contexto brasileiro repressor dos anos 1970. Em suas sonoridades, percebem-se muitas harmonias com predomínio de dissonâncias, instrumentação orquestral, guitarras, baixos, percussão sempre bem variada (ver descrição, abaixo, na análise da canção Casa Encantada), combinados com instrumentos eletrônicos mais modernos como teclados e sintetizadores.

\section{Análise das canções: sonoridades e identidades diversas}

Tendo em vista o interesse pelas sonoridades do grupo e a delimitação deste espaço de reflexão em forma de artigo, optou-se em discutir alguns excertos das seguintes canções e seus respectivos discos: Tributo ao Sorriso,9 do compacto de 1970; Rock do Elvis, do disco Terço (1973); Criaturas da Noite e Queimada, do LP Criaturas da Noite, gravado em 1975; Casa Encantada, do LP homônimo gravado em 1976; e, por último, a canção Mudança de Tempo do disco homônimo de 1978. Importante destacar que as análises não ocorrem de forma linear ou cronológica. Visam mostrar as diversas sonoridades construídas pelo grupo ao longo dos álbuns e compacto selecionados.

Partindo-se, por exemplo, da análise do LP Criaturas da Noite (1975), percebe-se, conforme a edição da Revista Bizz dedicada à história do rock no Brasil, que "O Terço era um dos conjuntos mais cultuados pela tribo roqueira de São Paulo, principalmente depois do lançamento do LP Criaturas da Noite, em 75".10 No encarte do disco, de acordo com o texto de Valdir Zwetsch, percebe-se o elogio à banda e ao seu espaço alcançado no cenário musical roqueiro do país:

[...] o Terço é um grande conjunto de rock - talvez o melhor do Brasil. Em seus shows, o conjunto vasculha com firmeza o repertório emocional do público e consegue sempre levá-lo a um nível de participação de invejável intensidade. De repente, puxado só pela força e beleza da música, o pessoal levanta dos lugares e dança pelos corredores, em cima das cadeiras e no palco. Quem não dança e quem não dança? - é porque está vivendo outra experiência equivalente qualquer. (Valdir Zwetsch)

Pode-se interpretar que o trecho, acima, compõe certa estratégia para formar e informar os fãs, ampliar público e vender o trabalho musical do grupo. Permite perceber, também, alguns traços da performance da banda, que leva os ouvintes/expectadores para a dança, para o movimento. Aqui, tem-se algumas aproximações com a estética

\footnotetext{
e quintas; Minha fé; Mudança de tempo; Descolada; Pela rua; Blues do adeus; Hoje é domingo (pede cachimbo).

9 Compacto V Festival Internacional da Canção Popular, Philips, 365.310 PB, 1970. Traz as seguintes faixas: Eu também quero mocotó; Tributo ao sorriso.

10 Cf. Revista Bizz, Especial Ídolos do Rock: a história do rock no Brasil, Anos 70: as ovelhas negras. Editora Azul, $1^{\circ}$ cad., s/d, p.12.
} 
do rock proposta pelo autor Bruce Baugh (1994), já mencionadas. Há, também, um tipo de escuta que se enquadra em certos padrões de participação mais contemplativos que são característicos do rock progressivo ('subgênero' do rock apropriado pelo grupo, conforme discutido mais à frente), sem se esquecer de outras viagens lisérgicas que poderiam ser experimentadas nesses shows. Ainda, segundo uma reportagem no Jornal de música e som, de 1975, "nos shows do Terço, no teatro Bandeirantes, várias cadeiras foram quebradas e todos assistiam o espetáculo em pé, nos braços das poltronas", o que mostra as diversas recepções e performances do público com relação à música do grupo.

Voltando para a análise da canção Criaturas da Noite, do LP homônimo acima citado, esta foi composta por Flávio Venturini e Luiz Carlos Sá. Os arranjos são de Rogério Duprat que, segundo Venturini, foi o responsável por apresentar-lhe a música da banda de rock progressivo Yes.11 Conforme relata o cantor: "nesse começo dos 70 [...] na primeira aula com o Rogério Duprat ele me mostrou o Yes e a gente começou a consumir essa música, que era muito forte na época" (VENTURINI, entrevista ao Museu do Clube da Esquina). ${ }^{12}$

Duprat, que havia participado dos arranjos do LP Tropicália ou Panis et Circensis, dos discos do trio Sá, Rodrix \& Guarabyra e da dupla Sá \& Guarabyra (inclusive o disco Nunca, citado anteriormente), pretendia, segundo Regiane Sanches Gaúna:

[...] adaptar a música sertaneja ao ritmo do rock. No entanto, Duprat afirma que o projeto não se restringia apenas à música sertaneja, mas, todo e qualquer ritmo brasileiro possível de integrar-se com as guitarras [fala de Duprat], ou seja, seu objetivo era transferir o instrumental do rock para a música popular brasileira (GAÚNA, 2004, p.2-3).

A autora cita, ainda, uma fala do próprio Duprat, numa entrevista em 1999, dizendo que sua proposta "seria uma injeção de modernidade. A bronca era que só se fazia sambas tocados com os instrumentos acústicos brasileiros" (DUPRAT apud GAÚNA, 2004, p.3). Por este pequeno depoimento, pode-se imaginar a importância de Duprat para o grupo em discussão.

Toda a canção Criaturas da Noite é cantada em coro a 4 vozes com predomínio de timbre agudo, por vezes em falsetes, alternando intervalos de uníssono e sexta (ou terça).

A utilização da voz aguda, com falsetes e em duas ou mais vozes, conforme já explicitado, é um dos recursos timbrísticos explorados pelos integrantes d'O Terço, garantindo uma marca sonora expressiva do grupo, um traço diacrítico (BARTH, 1998).

É interessante reparar que o arranjo e a orquestração enfatizam o aumento da massa sonora (Fig. 1) na música. A partir de 2'35" (comp. 76), da gravação original, so-

\footnotetext{
11 Embora não haja consenso e nem mesmo aceitação do rótulo progressivo pelos seus adeptos, pode-se caracterizar tal subgênero do rock como aquele que apresenta as seguintes características: composições longas, melodias e harmonias mais complexas do que o rock convencional (SANTOS, 2008, p.29), aproximações com a técnica e a estética da música 'erudita'. Exemplos desse estilo de rock encontram-se em bandas como Pink Floyd, Yes, Gênesis, entre outras.
}

12 Entrevista disponível em <http://www.museuclubedaesquina.org.br/museu/depoimentos/flavio-venturini/>. Acesso em 04 mar.2015. 
mam-se à massa orquestral a bateria, o baixo e o solo de guitarra em substituição ao coro, enfatizando uma sonoridade mais próxima ao rock.

Percebe-se que no momento em que a orquestra realiza os acordes agudos, em contratempo, estabelece-se uma analogia aos próprios sons da noite - ou das criaturas da noite - conforme na passagem "Eu te espero chegar/ vendo os bichos/ sozinho à noite". Neste momento, a melodia atinge seu ponto culminante inferior, não mais em coro, mas em uma voz, enfatizando o indivíduo sozinho.

\begin{tabular}{|l|l|l|l|l|l|}
\hline Compassos: & 01 a 07 & 08 a 15 & 16 al Fine & 39 a 45 & 76 al Fine \\
\hline & & & & $\begin{array}{l}\text { Cordas no } \\
\text { agudo em }\end{array}$ & Guitarra \\
\hline & & & & Contratempo & Baixo \\
\hline & & & Orquestra & Orquestra & Bateria \\
\hline & & Voz e Coro & Voz e Coro & Voz Solo & Orquestra \\
\hline & Solo de Piano & Solo de Piano & Solo de Piano & Solo de Piano & Solo de Piano \\
\hline
\end{tabular}

Fig. 1: Diagrama da massa sonora do arranjo de Criaturas da Noite.

A letra da canção trata, então, de elementos da natureza e também da condição do cantor, onde o eu lírico mostra sua solidão, reflexão e percepção dos elementos da noite:

As criaturas da noite/ num vôo calmo e pequeno/ procuram luz aonde secar/ o peso de tanto sereno/ os habitantes da noite/ passam na minha varanda/ são viajantes querendo chegar/ antes dos raios de sol/ Eu te espero chegar/ vendo os bichos/ sozinho na noite/ distração de quem quer esquecer/ o seu próprio destino/ Me sinto triste de noite/ atrás da luz que não acho/ sou viajante, querendo chegar/ antes dos raios de sol.

Por sua vez, a canção Casa Encantada, presente no LP homônimo de 1976, é também de composição de Flávio Venturini e Luiz Carlos Sá. A instrumentação conta com viola caipira, órgão elétrico e sintetizador, executados por Flávio Venturini, que também faz a voz solo. Sérgio Hinds toca viola e participa dos vocais. O baixo é por conta de Sérgio Magrão que também faz os vocalizes. Luiz Moreno atua no violão, no vocal e no caxixi. Tem, ainda, a participação do músico Zé Eduardo no tubo com água, tamboretes, triângulo, nozes e cincerro, e de Cesar de Mercês tocando flauta transversa. Encontram-se, em Casa Encantada (Fig. 3), certas aproximações com a canção Criaturas da Noite (Fig. 2), no que se refere ao contorno rítmico-melódico e à harmonização. Tem, também, a mesma ideia (ou mesmo tema) de encanto e de místico de Criaturas da Noite. 


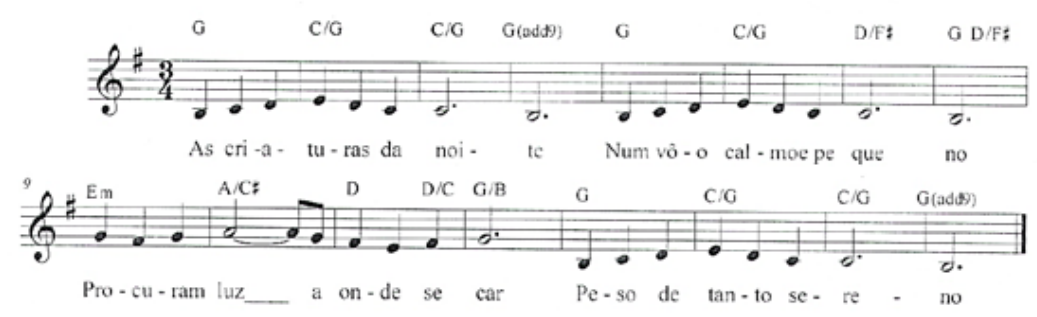

Fig. 2: Melodia da voz principal, com harmonia, da canção Criaturas da Noite.

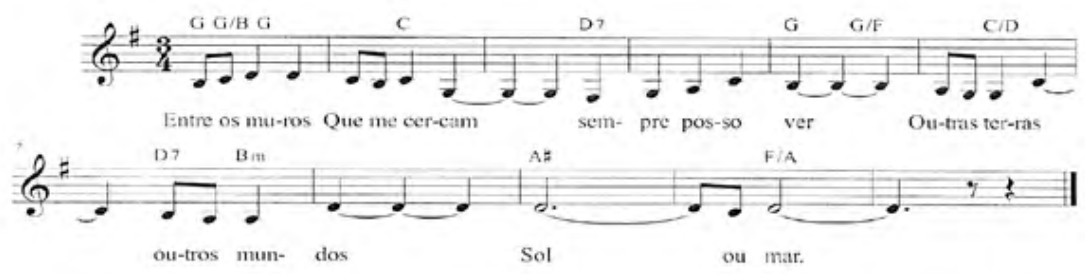

Fig. 3: Melodia da voz principal, com harmonia, da canção Casa Encantada.

Contudo, percebe-se, a partir da escuta da canção Casa Encantada, uma instrumentação com tendência sonora diferenciada daquela de Criaturas da Noite. A utilização de tipos diversos de percussão (como o tubo com água, por exemplo) e da viola sugere, em Casa Encantada, uma atmosfera sonora que remete à paisagem rural. A viola, por exemplo, é percebida no espaço e também no imaginário (representação) social brasileiro da época, e ainda nos dias atuais, como um instrumento característico do campo, associado ao contexto rural ou de cidades do interior. Nesse caso, a proposta da banda O Terço, sob influência do trio Sá, Rodrix \& Guarabyra e da dupla Sá \& Guarabyra, nos anos 1970, era a de combinar instrumentos elétricos (como as guitarras) e acústicos (como o violão e a viola), demonstrando a relação entre campo e cidade, tradição e modernidade. Tal relação e representação ficou rotulada pelo público, mídia, e apropriada por esses artistas, de rock rural..$^{13}$ Importante atentar para o fato de que a viola, na produção desses músicos, era eletrificada, portanto, fazendo parte de certo experimentalismo e de certa relação entre tradição e modernidade, ou seja, um instrumento do campo ou do interior utilizado dentro dos parâmetros eletrificados da cidade e da indústria musical. É o que afirma, por exemplo, o cantor Luiz Carlos Sá, ao explicar sobre o rock rural em artigo para a revista USP:

Na realidade o que fizemos de mais acertado foi justamente mirar na demolição de certos preconceitos arraigados naquele público jovem-classe-média-universitária que nos acolheu de princípio: enquanto Rodrix ressuscitava o então desprezado acordeão e partia também para a execução de instrumentos vistos como "exóticos", como cravo, celesta, harpsicórdio, etc., eu eletrificava e experimentava diferentes afinações na viola caipira de dez cordas, antes esnobada 
como instrumento menor, enquanto Guarabyra resgatava os sons das barrancas do São Francisco, largamente ignorados por um país que - ancorado no eixo Rio-São Paulo - não conhecia o Brasil real. Dessa mistura de três cabeças de formação e direções aparentemente divergentes foi que surgiu o que se pode chamar de rock rural (SÁ, 2010, p.129).

A canção Casa Encantada inicia-se com uma introdução na flauta, seguindo a mesma linha melódica da voz solo de Flávio Venturini. A base harmônica fica por conta das violas e do violão. Destaque para os vocais também com o predomínio de falsetes. A canção foi composta em um sítio, numa propriedade rural situada na estrada BR 116, Km 48, em São Paulo.14 Há um convite para aqueles que queiram compartilhar do meio natural e que desejam viver em amizade, em harmonia. Espera-se, na varanda, um amigo ou um amor. Trata-se de um desejo de vida bucólica, longe da cidade. O cantor, nos versos "entre os muros que me cercam/ sempre posso ver/ outras terras, outros mundos/ sol ou mar" (conforme Fig. 3 e letra, abaixo), mostra sua transcendência com relação aos limites do próprio corpo, à sua percepção e aos limites da própria casa, para ver e experimentar outras possibilidades de vida (sem desconsiderar, também, o momento de repressão que a sociedade brasileira vivia). Percebe-se, na letra, que tais ideias se aproximam das experiências e vivências contraculturais:

Entre os muros que me cercam/ sempre posso ver/ outras terras, outros mun$\mathrm{dos} / \mathrm{sol}$ ou mar/ entre os quartos onde moro/ passa um corredor/ onde o teto tem estrelas/ pra me guiar/ uma luz sempre acesa/ esperando chegar/ um amor na varanda/ um amigo na mesa/ qualquer um viajante/ que se queira encantar/ pelos quartos vazios/ pelas salas do mar.

Sobre as possíveis influências contraculturais na canção, nota-se que no final dos anos 1960 ocorre, no Brasil, a apropriação, por parte da juventude e de intelectuais, da chamada contracultura, que veio dos contextos políticos e sociais dos EUA e partes da Europa. A ideia era que cada um pudesse ficar na sua, longe dos modismos e da modernização dos grandes centros. Experimentou-se a saída para o campo, as experiências psicodélicas com as drogas, as comunidades tanto no campo quanto nas cidades. Era o 'cair fora' do sistema. E, segundo Carlos Alberto Messeder Pereira (1992), o rock foi a manifestação musical que melhor expressou os anseios de liberdade da juventude do período. As bandas brasileiras de rock também se aproximaram dessa contracultura em seu som, vestuário e/ou comportamento. Conforme o encarte abaixo (Fig. 4), do LP Casa Encantada, percebe-se o visual dos músicos próximo ao que era encontrado entre a juventude adepta da contracultura: aparece o cantor Flávio Venturini (à esquerda, canto inferior) de cabelos compridos, sem camisa, numa postura de liberdade e de contato com a natureza; na parte inferior do encarte, observa-se a performance dos músicos em show, também com cabelos compridos, executando o rock e com roupas que remetem ao universo contracultural (ver detalhe na Fig. 5).

Sobre o título e o tema da música nota-se que a casa encantada, a que se refere a 
canção, pode estar ou ser construída em qualquer lugar. Conforme a capa do LP (Fig. 6), a casa é uma projeção, pode ser imaginada em qualquer espaço, fazendo parte do imaginário e dos anseios de qualquer pessoa. As fotos do encarte mostram, além das aproximações dos integrantes com a natureza, as relações com a modernidade, onde há, também, imagens do grupo em shows (Fig. 5) e no processo de gravação do álbum (Fig. 7). Os artistas falam de natureza e utilizam os elementos modernos de gravação, de instrumentos elétricos e eletrônicos para elogiarem o meio natural. Estabelecem, desse modo, relações com o tradicional (o campo) e o moderno (aparelhagens, microfones, guitarras e modos de gravação de discos).

Ainda com relação à contracultura é importante destacar que, antes mesmo das influências contraculturais, o próprio Flávio Venturini fala de suas experiências no interior de Minas Gerais, nos tempos de infância:

Eu sempre gostei muito de mato, essa coisa, eu sou um garoto de cidade, mas que sempre adorou ir pro mato [...] Eu pegava um trem na estação de Belo Horizonte, ali na Central mesmo, e ia para Bambuí. Chegava lá às cinco da madrugada, sozinho com minha mala. (VENTURINI, entrevista ao Museu do Clube da Esquina).

O cantor transita entre a capital e o interior mineiro, vivenciando as experiências e os contrastes entre grandes e pequenas cidades. Encontram-se, por exemplo, essas referências nas letras das canções aqui analisadas, na utilização e combinação de violas e guitarras, e nos sons de percussão que remetem à paisagem sonora do campo, do mato, do meio rural.

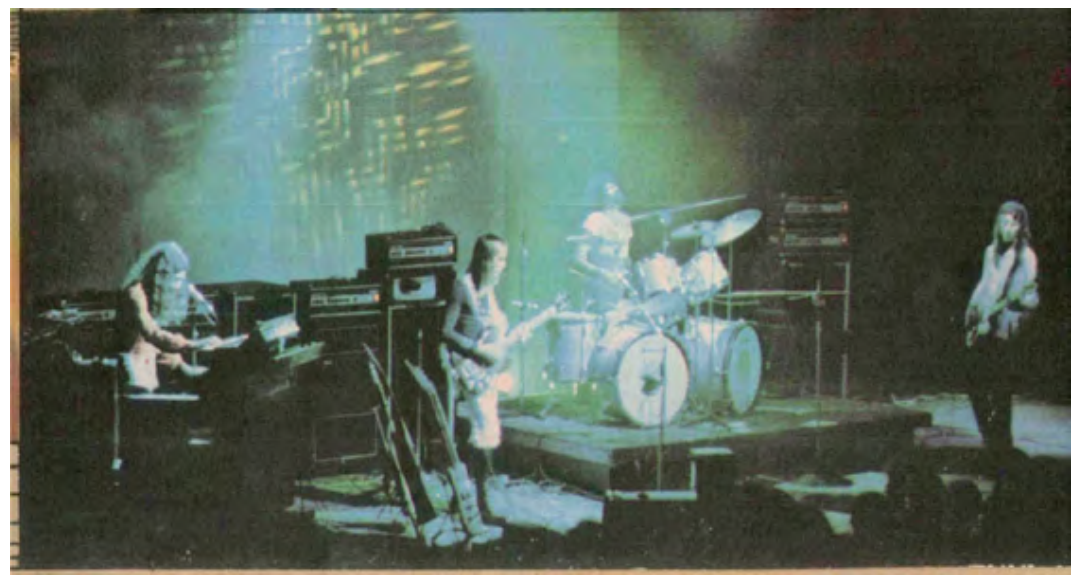

Fig. 4: Detalhe do encarte do LP Casa Encantada, mostrando a performance do grupo em show. 


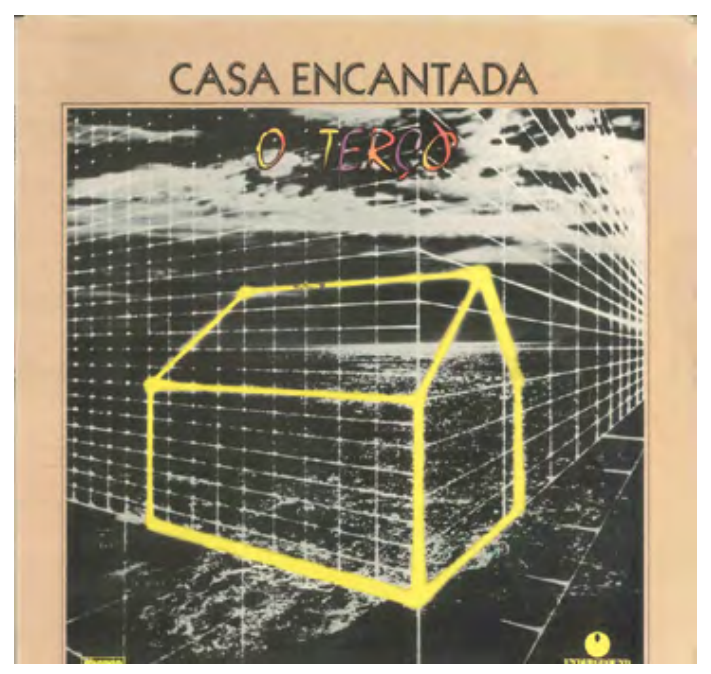

Fig. 5: Capa do LP Casa Encantada.

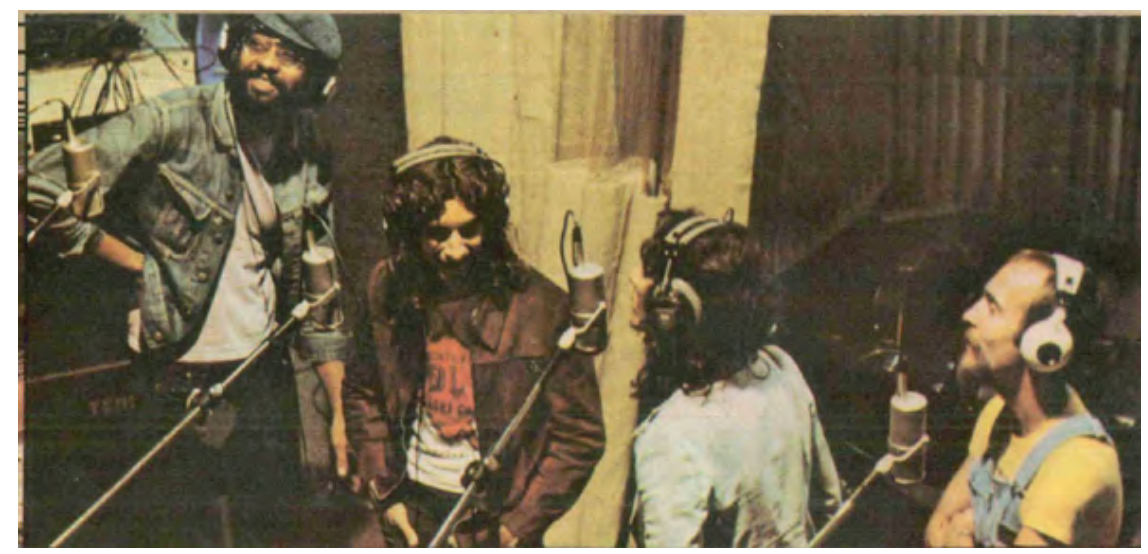

Fig. 6: Detalhe do encarte do LP Casa Encantada, mostrando os músicos no processo de ensaio e de gravação.

Importante destacar que, segundo Flávio Venturini, a sonoridade específica das canções, acima, partiram das influências que o cantor teve do rock progressivo e do que ele chamou de música mineira. Segundo o compositor:

O Genesis15 foi uma banda que nos influenciou muito, porque é uma banda que tem muita harmonia e a música mineira tem isso, então eu acho que a gente se identificou muito com aquela influência clássica e erudita que eles tinham. Eu digeri isso na minha música e levei para o grupo O Terço. Quando eu comecei no grupo $O$ Terço, eles vinham de um período bem folk, que tocava nos festivais de música brasileira, depois eles passaram para uma coisa mais hard rock, e quando eu entrei, levei uma linguagem progressiva que deu supercerto na época. Eu acho que $O$ Terço foi a grande banda de rock progressivo no Brasil de todos os tempos. (VENTURINI, entrevista ao Museu do Clube da Esquina).

Sérgio Magrão, também em depoimento ao Museu do Clube da Esquina16, enfa-

Para as eventuais influências do grupo Genesis, sugere-se a escuta dos discos Trespass, de 1970, e Nursey Cryme, de 1971. Encontram-se, nesses discos, teclados, sintetizadores, violões, guitarras, baixo, flautas, bateria e percussão, com sonoridades que se aproximam às da produção d'O Terço nos LP's Criaturas da Noite e Casa Encantada. 
tiza essa influência de Minas Gerais em sua formação e na música da banda:

[...] no começo, a música mineira me ensinou a questão da harmonia. Harmonia bem elaborada, porque aí você tem condições. Uma harmonia que você acha que nem vai caber em determinada melodia. Vem à melodia, aí é que surpreende mais ainda. (MAGRÃO, entrevista ao Museu do Clube da Esquina).

A harmonia da música mineira, 17 a que Flávio Venturini e Sérgio Magrão fazem menção, refere-se às construções musicais do Clube da Esquina. Percebem-se, nas canções Criaturas da Noite e Casa Encantada, acima analisadas, os arranjos com harmonias dissonantes18 e inversões, presentes nas produções dos artistas do Clube, além dos contrastes e coloridos timbrísticos de orquestração vindos das influências de Rogério Duprat. Mas, as harmonias mais elaboradas a que se refere Venturini também são encontradas nas canções de bandas que o influenciou, como o Gênesis e o Yes. É bom lembrar que as harmonias dissonantes ou mais elaboradas não são e não eram, àquela época, atributos exclusivos dos artistas do Clube da Esquina.

Outra ideia de mineiridade para os artistas, refere-se ao sentimento que é transmitido, por exemplo, na voz de Milton Nascimento. Para Sérgio Magrão, música mineira tem a ver com a emoção evocada, sobretudo, por meio do canto:

O mais importante que eu acho, assim, da música mineira, para mim, música tem que emocionar, tem que te fazer chorar, tem que te fazer arrepiar. Sabe, não tem jeito. Claro que existe música para dançar, não sei o quê, mas o tipo de música que é feito ali, é feito com sentimento. Se você vê o Milton cantar não tem como não encher os olhos. (MAGRÃO, entrevista ao Museu do Clube da Esquina).

Além das influências do rock progressivo das bandas Gênesis e Yes e do trabalho do Clube da Esquina, Flávio Venturini cita, também, o apoio dos músicos Luiz Carlos Sá e Gutemberg Guarabyra. Segundo Venturini, "Sá e Guarabira estavam também sempre por perto, foram pessoas que influenciaram, que deram a maior força" (VENTURINI, entrevista ao Museu do Clube da Esquina). O grupo gravou a canção Pássaro do trio Sá, Rodrix \& Guarabyra, no LP Casa Encantada.19 No caso, a proposta do rock rural desses músicos, como já mencionado, era combinar instrumentos elétricos com viola caipira, letras que falavam do campo e da cidade, tensões e vivências entre um e outro, encontradas em diversas canções da dupla Sá \& Guarabyra. Essas influências são também percebidas na música Queimada, do LP Criaturas da Noite:

\footnotetext{
17 Este termo, embora usual em Belo Horizonte e em algumas cidades mineiras, não apresenta uma definição precisa e nem um consenso em relação a ele. Um estudo importante que vem sendo desenvolvido, a este respeito, é a tese de doutorado no PPGMUS-UFMG de Daniel Menezes Lovisi, "A singularidade do violão mineiro: um estudo sobre a produção de violonistas compositores do estado e a relação de suas obras com a identidade mineira".

18 Entendendo dissonância conforme as definições de Bohumil Med: para o músico, professor de trompa e autor da obra Teoria da Música, "dois ou mais sons simultâneos produzem o efeito de consonância ou dissonância". Sendo assim, chama-se consonância a sonoridade que proporciona repouso e estabilidade na música, quando as notas se harmonizam de forma a trazer equilíbrio para quem escuta. Já uma dissonância, "proporciona uma sensação de movimento e tensão", fazendo com que o ouvinte escute dois ou mais sons ao mesmo tempo e que podem parecer indefinidos aos ouvidos (MED, 1996, p.97).

19 A canção Pássaro foi censurada no segundo LP do trio, Terra, de 1973 (MARCONDE, 1998, p.701). Só foi gravada no disco Quatro, em
} 1979, da dupla Sá \& Guarabyra. 
Vira poeira/ vira fogueira/ vira poeira/ fogo, fogueira/ vira o chão/ vira fogueira/ vira o chão/ vira poeira/ de carvão/ de carvão/ Ah, vira poeira.

A letra é de autoria de Flávio Venturini e Cesar de Mercês. Os instrumentos na canção são a viola, o contrabaixo e a percussão. Os arranjos vocais são em coro e em falsete. Além das influências instrumentais do rock rural, de combinar violões ou violas com instrumentos elétricos, a preocupação com o meio ambiente e a denúncia sobre queimadas, presente na música, se aproximam do pensamento da contracultura. Antônio Risério (2005), por exemplo, sublinha alguns pontos positivos dos movimentos contraculturais no Brasil, e em outras partes do mundo, tais como o pacifismo, o feminismo e a questão ambiental:

No caso do ambientalismo, algumas coisas merecem destaque. A questão da relação homem/natureza, que foi um dos temas centrais do contraculturalismo, emergiu no contexto da exacerbação antitecnológica que dominou o movimento, em decorrência da crítica à sociedade industrial e de 'consumo', ou plastic society, que levava a humanidade a cometer crimes contra si mesma. (RISÉRIO, 2005, p.27).

A contracultura desempenhou papel importante na reflexão sobre os problemas que a modernização capitalista poderia acarretar e acarretou ao meio natural.

No depoimento anterior de Flávio Venturini, nota-se, em seu discurso, as diversas sonoridades da banda. Venturini conta, por exemplo, que quando começou no grupo, $O$ Terço vinha de uma experiência musical dos Festivais. Exemplo desse tipo de sonoridade é encontrado na música Tributo ao Sorriso, gravada em compacto, no ano de 1970, e classificada no V Festival Internacional da Canção da TV Globo.

A música conta com piano, bateria, percussão, baixo e guitarra. $O$ jogo de vozes em terças e sextas está presente. A letra tem uma temática existencial (Fig. 8). Há predomínio de harmonias dissonantes e com inversões. Essas características, como já visto, vão continuar ao longo do trabalho da banda.

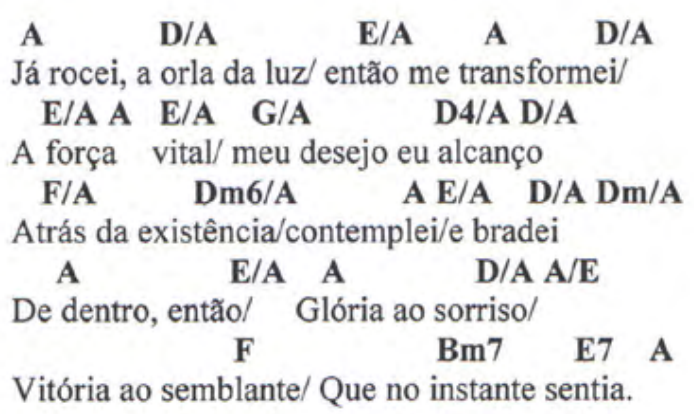

Fig. 8: Cifragem descritiva da canção Tributo ao sorriso. Disponivel em <http://www.cifraclub.com.br/o-terco/tributo-ao-sorriso/>. Acesso em 01 nov.2015. Revisado pelo autor. 
Sérgio Magrão, por sua vez, fala do som d'O Terço na época:

Era César de Mercês, Vinícius Cantuária na bateria e o Sérgio Hinds na guitarra. Aí já era um som, era progressivo, mas era um progressivo diferente. Porque a tecladaria não rolava, aquela tecladaria pesada. Veio a ter essa tecladaria quando Flávio entrou, foi diferente. No começo, eles faziam o que eu chamo de música para festival, música bonita, bem armada, com vocal. Que era na época do Jorge Amiden, do Vinícius Cantuária e do Sérgio Hinds [...] (MAGRÃO, entrevista ao Museu do Clube da Esquina).

Flávio Venturini cita, ainda, que depois o grupo passou para um som mais hard rock. Na canção Rock do Elvis, do segundo disco, em 1973, por exemplo, encontram-se as influências do rock clássico e do blues.

Seção A:

\begin{tabular}{|c|c|}
\hline & G7 \\
\hline & Preciso de um pouco de tempo para falar com vo \\
\hline & $\begin{array}{lll}\text { D7 } & \text { G7 }\end{array}$ \\
\hline & Domingo no cinema quem sabe pode acontecer \\
\hline \multirow[t]{8}{*}{ Seção B: } & C7 \\
\hline & Veja o filme no jornal \\
\hline & G7 \\
\hline & E depois ligue pra mim \\
\hline & C7 \\
\hline & Leve o seu irmão se quiser \\
\hline & D7 \\
\hline & Que eu vou levar o meu irmão também. \\
\hline \multirow[t]{2}{*}{ Refrão: } & $\begin{array}{llllll}\text { G7 } & \text { Bb } & \text { C } & \text { G7 } & \text { G7 } & \text { Bb }\end{array}$ \\
\hline & Baby! Baby! Baby! Oh, Yeah!/ Baby! Baby! Bal \\
\hline \multirow[t]{5}{*}{ Seção A: } & \\
\hline & G7 \\
\hline & Depois do cinema sorvete juntos vamos tomar \\
\hline & G7 \\
\hline & E como no tempo do Elvis, rock vamos dançar \\
\hline \multirow[t]{8}{*}{ Seção B: } & \\
\hline & $\begin{array}{l}\text { C7 } \\
\text { Pegue o meu irmão e o seu }\end{array}$ \\
\hline & G7 \\
\hline & Deixe naquele lugar \\
\hline & C7 \\
\hline & Compre balas e chicletes \\
\hline & D7 \\
\hline & Que esse roquinho ainda vai durar. \\
\hline
\end{tabular}

Seção B:

$$
\begin{aligned}
& \begin{array}{llllllll}
\text { G7 } & \text { Bb } & \text { C } & \text { G7 } & \text { G7 } & \text { Bb } & \text { C } & \text { G7 }
\end{array} \\
& \text { Baby! Baby! Baby! Oh, Yeah!/ Baby! Baby! Baby! Oh, Yeah! }
\end{aligned}
$$

$$
\begin{aligned}
& \text { C7 } \\
& \text { Pegue o meu irmão e o seu } \\
& \text { G7 } \\
& \text { Deixe naquele lugar } \\
& \text { C7 } \\
& \text { Compre balas e chicletes } \\
& \text { D7 } \\
& \text { Que esse roquinho ainda vai durar. }
\end{aligned}
$$

Refrão (estilo vocal chamado-resposta):
G7 Bb
C G7
Baby! (baby) Baby! (baby) Baby! (baby) Yeah!Yeah!Yeah!Yeah!...

Fig. 9: Cifragem descritiva da canção Rock do Elvis. Transcrição do autor. 
Os instrumentos presentes na música são o saxofone, o piano, a bateria, o baixo e a guitarra. A seção rítmica é por conta da guitarra com o predomínio de pulsos quaternários. Os solos são de guitarra, com efeitos de distorção, notas sustentadas e sequência melódica I, IV e V, típicos do blues e do rock and roll clássico. ${ }^{20}$

A música segue a progressão harmônica 17, IV7 e V7, com os acodes em Sol maior com sétima, Dó maior com sétima e Ré maior com sétima (G7, C7 e D7), também presentes no blues e que, quando acelerados, no ritmo do rock and roll, e com as distorções da guitarra, se aproximam do estilo ou subgênero hard rock (ROSA, 2007, p.79). O vocal é extrovertido e alegre. A letra apresenta uma narrativa pessoal cuja temática é típica do rock and roll dos anos 50 e 60: namoro, curtição, som e dança. A estrutura da letra segue a forma A-B-A-B-B com cada seção intercalada por um pequeno refrão (Fig. 9). O estilo do vocal, no último refrão, é do tipo chamado e resposta (vocalização entre parênteses, na palavra norte-americana "baby", que tem significado bem íntimo para quem a pronuncia), também característico do rock. Percebem-se, assim, outras formas de o grupo cantar e tocar o seu rock.

Sobre a relação entre música e modernidade, encontrada no grupo O Terço, percebe-se, no prefácio de Luiz Carlos Sá, contido no encarte do LP Casa Encantada, que há a discussão sobre música brasileira, onde "o Terço [seria] o melhor grupo de música moderna". Sá põe em discussão se a banda fazia música brasileira, universal ou de raízes, sendo que para eles não importava, mas sim, o prazer, o "barato" de escutar o grupo. Sá destaca que a banda O Terço faz "um trabalho seriamente significativo no contexto atual da música popular moderna".

Nota-se que para Luiz Carlos Sá, acima, bem como para a banda O Terço, música popular brasileira (moderna) é aquela que engloba todos os elementos sonoros disponíveis. Interessante, também, as discussões do grupo quando da saída de Venturini e da preparação do novo disco Mudança de Tempo. Segundo o depoimento dos artistas, na revista Música, em 1977:

O problema todo é que fazemos um som brasileiro que se caracteriza e identifica com o rock. Mas quando o pessoal vê a gente com uma guitarra na mão já pensa logo em rock pesado, o que limita o trabalho e a criação do grupo.

O discurso, acima, é do guitarrista Sérgio Hinds e mostra a discussão do grupo sobre rock e música brasileira. Eles defendem liberdade de criação dentro do próprio rock considerado, para muitos (segundo os artistas), música estrangeira. Os músicos d'O Terço falam de sua música, de seu rock, como universal, sem fronteiras e também do projeto de exportá-lo para outros países. Conforme reportagem da Revista POP, de 1975:

[...] se o rock alemão invadiu o mundo, por que o rock brasileiro não deve tentar? Nosso trabalho é sério, elaborado e profissional. E rock, todo mundo sabe, é uma linguagem universal, sem fronteiras.

20 Segundo Paul Friedlander, o rock and roll, em sua formação clássica, teve, como representativo, os artistas Fats Domino, Bill Haley, Chuck Berry e Little Richard (FRIEDLANDER, 2012, p.43-63). 
As sonoridades percebidas nas canções, aqui analisadas, mostram a proposta dos músicos de construir uma identidade plural em seu rock e para a canção brasileira. Eles não se preocupavam com as raízes da música brasileira, como os artistas do nacional-popular.21 Combinaram guitarras, violas, violões, orquestração, instrumentos de percussão e sintetizadores. Assim, mostraram um rock que também dialogou com seu contexto histórico: a modernização do país, que implicou no crescimento das grandes cidades, gerando a nostalgia de uma vida no campo; o avanço da indústria cultural e a instalação de gravadoras multinacionais. Estas, contavam com aparelhagem moderna como mesas de dezesseis canais, sintetizadores e guitarras. Flávio Venturini relata sobre essa experiência ao visitar a gravadora EMI-Odeon, no período das gravações dos discos Criaturas da Noite e Casa Encantada:

Nessa época, as gravadoras tinham os instrumentos. Instrumentos que na época a gente não conseguia ter, você chegava à gravadora e tinha. Tinha um piano Fender, tinha um órgão Hammond, várias guitarras, vários baixos importados e violões e era uma festa para os músicos. Um instrumento bom faz a cabeça de qualquer músico e o ambiente também faz. No estúdio, eles usavam as mesmas mesas em que os Beatles gravavam no estúdio da Odeon, eram bem semelhantes. Eu conheci os estúdios da Odeon, não os de Londres, mas os dos Estados Unidos, os de Los Angeles, e eram todos parecidos. Pra gente era uma festa encontrar aquilo. (VENTURINI, entrevista ao Museu do Clube da Esquina).

Ainda sobre o contexto dos anos 1970, segundo Venturini o rock era, para ele e outros artistas, uma válvula de escape contra a ditadura. Conforme relata: "nos shows d'O Terço a gente sentia que era muito legal para o jovem ir ao show de rock nessa época" (VENTURINI, entrevista ao Museu do Clube da Esquina). Contudo, a banda, nesse período, não ostentava uma postura política de enfrentamento ao regime militar. Segundo afirma Flávio Venturini:

Eu não me lembro de censura a nossas músicas. A gente sentiu o peso da ditadura sim, morando em São Paulo de 1974 a 1978. A barra era muito pesada, a gente era muito parado na rua, eu com cabelos imensos e aquela cara de hippie (risos). Teve uma ocasião em que pararam a gente na saída de um show, dando geral na rua. A gente sabia de presos políticos [...] a gente sabia de muitas histórias de presos políticos, de tortura, a gente estava consciente do que estava acontecendo. Eu acho que a música era uma válvula de escape, é só ver a riqueza da música brasileira dessa época. (VENTURINI, entrevista ao Museu do Clube da Esquina).

É claro que também não faltaram críticas ao contexto da época. Na canção Mudança de Tempo, do LP de 1978, os músicos cantam:

Acordar/ que o tempo parou por aqui/ espalhar/ as nuvens que cobrem o céu/ acordar/ que o tempo parou por aqui/ espalhar/ as nuvens que cobrem o céu/ tomara que um pé de vento/ passe por cá/ tomara que a correnteza/ teime em passar/ quem dera que a maré suba/ invadindo o cais/ pois quando amanhecer de novo/ haverá lugar/ tomara que um pé de vento/ passe por cá/ tomara que a

21 Para uma discussão sobre o nacional-popular e as ideias sobre identidade nacional de vários artistas, nos anos 1960 e 1970 , ver RIDENTI, Marcelo. Em busca do povo brasileiro: artistas da revolução, do CPC à era da tv. RJ: Record, 2000. 
correnteza/ teime em passar/ quem dera que a maré suba/ invadindo o cais/ pois quando amanhecer de novo/ haverá lugar para o sol.

Há, aqui, a crítica e os apontamentos para se pensar numa mudança de rumos para o país. Uma ideia de esperança, de libertação e de mudanças que precisavam acontecer urgentemente.

Contudo, percebem-se que, apesar e para além da ditadura, a banda O Terço e outros grupos de rock queriam produzir e tocar sua música. Suas canções dialogaram com o momento repressor dos anos 1970, mas constituíram-se como vozes dissonantes em meio à produção engajada ou de consentimento à ditadura civil-militar. Com apropriações e influências da contracultura (em seu visual ou em suas aproximações com o meio rural), seja no gênero rock, ou melhor dizendo, em seus vários rocks e em suas performances, os artistas d'O Terço construíram várias sonoridades e cantaram e tocaram as características e o contexto do Brasil do período.

\section{Representações, apropriações e identidades múltiplas na canção brasileira}

A análise das canções, utilizadas aqui como fontes históricas e articuladas com os conceitos de identidade e cultura, abre possibilidades de entendimento da realidade social de certos grupos e de suas representações sobre o contexto brasileiro nos anos 1970.

Tomando como exemplo o rock produzido pela banda $O$ Terço, percebe-se que sua proposta, como grupo, não seguiu apenas uma vertente deste gênero. Conforme demonstrado, suas músicas passaram pelo hard rock, rock rural, progressivo, música de festival etc. Embora tais conceitos ou subgêneros do rock careçam de um estudo mais aprofundado, eram utilizados no discurso dos integrantes do grupo.

Dessa forma, na década de 1970, em plena ditadura militar, um período de forte repressão política, social e cultural, ao se tomar, como exemplo, o gênero musical rock e suas ramificações como representativos de uma realidade, podem-se perceber certas características de uma sociedade marcada pelas contradições entre modernidade e tradição, no contexto de cerceamento das liberdades.

Utilizando os conceitos de representação e apropriação, trabalhados pelo historiador cultural Roger Chartier (2002), é possível estudar e entender os diferentes grupos no período ditatorial com suas percepções e construções da realidade, e as diversas maneiras de se posicionarem no mundo. Ao se estudar as várias produções musicais no Brasil, com destaque, aqui, para o rock, podem-se compreender as práticas sociais que fazem reconhecer certa(s) identidade(s) e sua construção "como resultado sempre de uma relação de força entre as representações impostas por aqueles que têm [o] poder de classificar e de nomear e a definição, submetida ou resistente, que cada comunidade produz de si mesma" (CHARTIER, 2002, p.73). Dessa forma, é possível pensar, ao se tratar sobre o estudo da sociedade brasileira, para além das resistências ou imposições de qualquer indivíduo ou grupo, nas pluralidades de apropriação (usos da música), nos 
processos dinâmicos e nas diferenciações culturais no Brasil na década de 1970.

Ao cantar a cidade e o campo, a modernidade e a tradição, o amor e a liberdade, o grupo O Terço, e vários artistas (roqueiros) da época, propõem uma relação entre universos considerados contrastantes: ao mesmo tempo em que cantam a modernidade, eles se voltam para o campo, para a suposta tradição bucólica. E, conforme aponta o historiador Marcos Napolitano, a pluralidade de escutas e de gêneros musicais no Brasil, especialmente a dos anos 1970, segue como "objetos híbridos, portadores de elementos estéticos de natureza diversa, em sua estrutura poética e musical" (Napolitano, 2002 , p.2). Existe, desse modo, a possibilidade de se interpretar o que é o Brasil por meio da música. Esta não é apenas reflexo da sociedade, mas meio de conhecimento de uma época, de grupos, de indivíduos, enfim, de contextos diversos. A música, ou melhor dizendo, as diversas músicas, podem produzir conhecimento histórico, construir história.

Articulando-se o conceito de identidade com o conceito de cultura, pode-se afirmar que os atores sociais constroem seu pertencimento e o Estado, muitas vezes, não dá conta da construção homogênea de uma identidade nacional. Para Stuart Hall (1998), por exemplo, numa época de intensa globalização, em que ocorre uma fragmentação dos sujeitos, o sentimento de pertencimento dos indivíduos muda segundo o modo como o sujeito é interpelado ou representado. Para Hall, existe um 'jogo de identidades' que se apresentam como contraditórias, com cruzamentos e deslocamentos mútuos, não ocorrendo um alinhamento por uma identidade particular (seja de classe, profissão, gênero, política etc.).

Assim, não se pode pensar o conceito de identidade como vazio, frouxo ou inconsistente (BRUBAKER, 2001). O fato de as identidades serem constituídas, múltiplas, fluidas, não invalida o estudo das diversas formas de pertencimento. $O$ conceito de identidade deve ser pensado em seu contexto. Não é algo reificado, abstrato, ou passível de uma imposição 'de cima' (leia-se: Estado e formas de construção cultural de pertencimento homogêneo). Stuart Hall, por exemplo, fala de indivíduos ou grupos traduzidos, onde as identidades estão sujeitas ao plano histórico, sendo as fronteiras dissolvidas e as continuidades rompidas.

Desse modo, as identidades são construídas e o elemento identitário é sempre relacional (BARTH, 1998). Identidades constituídas historicamente e sujeitas a constantes mudanças. No caso da música, os elementos identitários são construídos por meio dos sons, do contexto político, social, econômico, cultural e também por meio da performance. Como nota-se nos encartes analisados, os artistas marcam uma identidade contracultural com seus cabelos compridos e visual hippie. Eles mantêm, também, alguns traços diacríticos em sua produção e performance, como a combinação de vozes. Porém, em suas sonoridades, encontram-se elementos que mostram outras identidades: o pertencimento ao campo quando utilizam a viola, a preocupação com o meio ambiente quando cantam contra as queimadas, suas experiências na cidade e com a modernidade, quando usam os equipamentos elétricos e eletrônicos em suas gravações e shows. Ou seja, eles acionam uma série de componentes que poderiam, a princípio, serem interpretados como contrastantes, ou sem um conteúdo homogêneo, mas que mostram, justamente, a complexidade da sociedade em que estão inseridos. 
Esses elementos nem sempre são acionados conscientemente. Os músicos não tinham um projeto de misturá-los para mostrar, à sociedade, os contrastes, mas utilizaram-se desses recursos porque eles estavam disponíveis em seu contexto social e, portanto, musical. Não são, dessa forma, engajados ou subversivos, mas estão nesse entrelugar, entre a metralhadora dos engajados, a queixada de burro do nacional-popular e o LSD da contracultura. Suas diversas sonoridades rock mostram um trabalho artístico, que dialoga com um tempo de experimentações e com a manifestação artística de um grupo, que trabalhou e trabalha com as linguagens que o rock pode proporcionar. Foge, nesse caso, de qualquer proposta de homogeneidade e de identidade nacional. Por isso, se constitui como fonte histórica importante para se entender outras formas de perceber e de representar a sociedade brasileira.

Música, cultura e identidade, nesse sentido, devem ser estudados de forma relacional, dentro do contexto histórico e material em que estejam inseridos, sem correr o risco de enrijecer tais conceitos. Numa perspectiva sincrônica e diacrônica, o historiador da música deve ter em mente que uma realidade é sempre construída. Cabe, então, o estudo atento daquilo que é verossímil no passado.

\section{Referências}

ALVES, Luciano (org.). O melhor de Flávio Venturini. SP: Irmãos Vitale. s/d.

BARTH, Fredrik. "Grupos étnicos e suas fronteiras". POUTGNAT, Philippe; STREIFF-Fenart, Jocelyne. Teorias da etnicidade. SP: Editora da UNESP, 1998.

BARTOLOMÉ, Miguel Alberto. "As etnogêneses: velhos atores e novos papéis no cenário cultural e político". Mana. 12(1), 2006, p.39-68.

BAUGH, Bruce. "Prolegômenos a uma estética do rock". Novos Estudos. São Paulo, CEBRAP, n. 38, p.15-23, 1994.

BRUBAKER, Roger. "Au-delá de l'identité". In: Actes de la Recherche em sciences sociales. 2001. vol. 139, n.1, p.66-85.

CHARTIER, Roger. À beira da falésia: a história entre incertezas e inquietudes. Porto Alegre: Ed. Universidade/UFRGS, 2002.

FRIEDLANDER, Paul. Rock and roll: uma história social. 7. Ed. RJ: Record, 2012.

GAÚNA, Regiane Sanches. Duprat e a tropicália. In: Anais do V Congresso da Seção Latino-Americana da Associação Internacional para o Estudo da Música Popular, IASPM -LA, Rio de Janeiro, 2004, p.1-11. Disponível em <http://www.iaspmal.net/wp-content/ uploads/ 2011/12/RegianeGauna.pdf>. Acesso em 05 abr.2010. 
HALL, Stuart. A identidade cultural na pós-modernidade. RJ: DP\&A, 1998.

MAGRÃO, Sérgio. Entrevista ao Museu do Clube da Esquina. Disponível em < http:// www.museuclubedaesquina.org.br/museu/depoimentos/sergio-magrao/>. Acesso em 04 mar.2015.

MARCONDE, Marcos A. "Sá e Guarabira". In: Enciclopédia da música brasileira: erudita, folclórica e popular, 1998, p. 701.

MED, Bohumil. Teoria da música. 4.ed. Brasília: Music Méd. 1996.

MELLO, Zuza Homem de. A era dos festivais: uma parábola. SP: Ed. 34, 2003. (Coleção Todos os Cantos).

MOLINO, Jean. "Facto musical e semiologia da música". In: SEIXO, Maria Alzira (Org.). Semiologia da Música. Lisboa: Veja, 1975, p.109-164.

NAPOLITANO, Marcos. História e Música: história cultural da música popular. Belo Horizonte: Autêntica, 2002.

PEREIRA, Carlos Alberto Messeder. O que é contracultura. Coleção Primeiros Passos. 8. ed. São Paulo: Editora Brasiliense, 1992.

RISÉRIO, Antônio (org.). Anos 70: trajetórias. SP: Iluminuras - Itaú Cultural, 2005.

ROSA, Pablo Ornelas. Rock underground: uma etnografia do rock alternativo. SP: Radical Livros, 2007.

SANTOS, Lincoln Meireles dos. O teclado eletrônico como um instrumento orquestral: análise e demonstração da peça Sir Lancelot and The Black Knight de Rick Wakeman. Dissertação (Mestrado), Música, Universidade Federal de Minas Gerias, Escola de Música, Belo Horizonte, 2008.

TAGG, Philip. Musicology and semiotics of popular music. Revista Semiotica n 66-1/3, p.279-298, 1987. Disponível em <http://tagg.org/articles/xpdfs/semiota.pdf>. Acesso em 08 nov.2015.

TROTTA, Felipe. "Gêneros musicais e sonoridade: construindo uma ferramenta de análise". Ícone, Universidade Federal de Pernambuco, v. 10, n.2, p.1-12, 2008.

VENTURINI, Flávio. Entrevista ao Museu do Clube da Esquina. Disponível em: http:// www.museuclubedaesquina.org.br/museu/depoimentos/flavio-venturini /. Acesso em 04 mar.2015. 


\title{
Discografia:
}

O TERÇO. Tributo ao sorriso - V Festival Internacional da Canção Popular. Philips, Compacto, 1970.

\author{
Têrço. Forma, Compacto, 1971. \\ Terço. Continental, LP, 1973. \\ .Criaturas da Noite. Underground/Copacabana, LP, 1975. \\ Casa Encantada. Underground/Copacabana, LP, 1976. \\ Mudança de Tempo. Underground/Copacabana, LP, 1978.
}

\section{Jornais e Revistas:}

Jornal de música e som. "O Terço: o início da euforia". RJ: Editora Vozes, 1975, p.8-9.

Revista Bizz. Especial Ídolos do Rock: a história do rock no Brasil, Anos 70: as ovelhas negras. Editora Azul, 1o cad., s/d, p. 12.

Revista Música. "O som funky e urbano do novo Terço". Nov. 1977, p.6.

Revista POP. "Nosso rock não tem fronteiras". Editora Abril, set. 1975, p.63. 